\title{
STUDIES ON THE PROCESS OF RECOVERING LOW-TEMPERATURE WASTE HEAT FROM A FLUE GAS IN A PILOT-SCALE PLANT
}

\author{
Piotr Szulc*, Tomasz Tietze, Kazimierz Wójs \\ Wrocław University of Technology, Faculty of Mechanical and Power Engineering, Wybrzeże \\ Wyspiańskiego 27, 50-370 Wrocław, Poland
}

\begin{abstract}
This paper presents studies carried out in a pilot-scale plant for recovery of waste heat from a flue gas which has been built in a lignite-fired power plant. The purpose of the studies was to check the operation of the heat recovery system in a pilot scale, while the purpose of the plant was recovery of waste heat from the flue gas in the form of hot water with a temperature of approx. 90 C. The main part of the test rig was a condensing heat exchanger designed and built on the basis of laboratory tests conducted by the authors of this paper. Tests conducted on the pilot-scale plant concerned the thermal and flow parameters of the condensing heat exchanger as well as the impact of the volumetric flow rate of the flue gas and the cooling water on the heat flux recovered. Results show that the system with a condensing heat exchanger for recovery of low-temperature waste heat from the flue gas enables the recovery of much higher heat flux as compared with conventional systems without a condensing heat exchanger.
\end{abstract}

Keywords: heat recovery, condensation, inert gas

\section{INTRODUCTION}

One method to increase the efficiency of power units in coal-fired power plants is the recovery of waste heat from the flue gas. However, in the majority of power plants currently operated or being constructed, the systems for the recovery or allocation of waste heat from the flue gas cool flue gas to a temperature higher than the temperature of their saturation (Wójs et al., 2010). Unfortunately, in this case the degree of cooling of the flue gas and the waste heat flux recovered are low. In order to increase the heat flux recovered, the authors proposed to equip such a system with a condensing heat exchanger. The function purpose of the heat exchanger installed is to increase the heat flux recovered through condensation of water vapour contained in the flue gas. Mathematical modelling and designing such a heat exchanger is a difficult task due to the complex model describing the heat transfer in the presence of inert gas, a concentration of water vapour, the effect of condensation, and a limitation resulting from a large heat flux that affects the overall dimensions of the exchanger (Chaojun et al., 2012; Chaojun et al., 2014; Dexin et al., 2012; Rączka et. al., 2014; Szulc et al., 2012; Szulc et al., 2013; Szulc et. al., 2015; Xiaojun et al., 2011). Results of laboratory tests (Tietze et al., 2014, Wójs et. al. 2015) were used to design and build a condensing heat exchanger for operation in a real lignite-fired power unit. 


\section{PILOT-SCALE PLANT}

The purpose of the studies was to verify the operation of a system with a condensing heat exchanger for waste heat recovery from flue gas in a real power unit of a coal-fired power plant. The pilot-scale plant was supplied with the flue gas from the combustion of lignite. A bypass supplying the condensing heat exchanger was made in the flue gas duct between the electrostatic precipitator and the desulphurization system. Figure 1 shows a general diagram of the pilot-scale plant, while Fig. 2 presents a view of the pilot-scale plant.

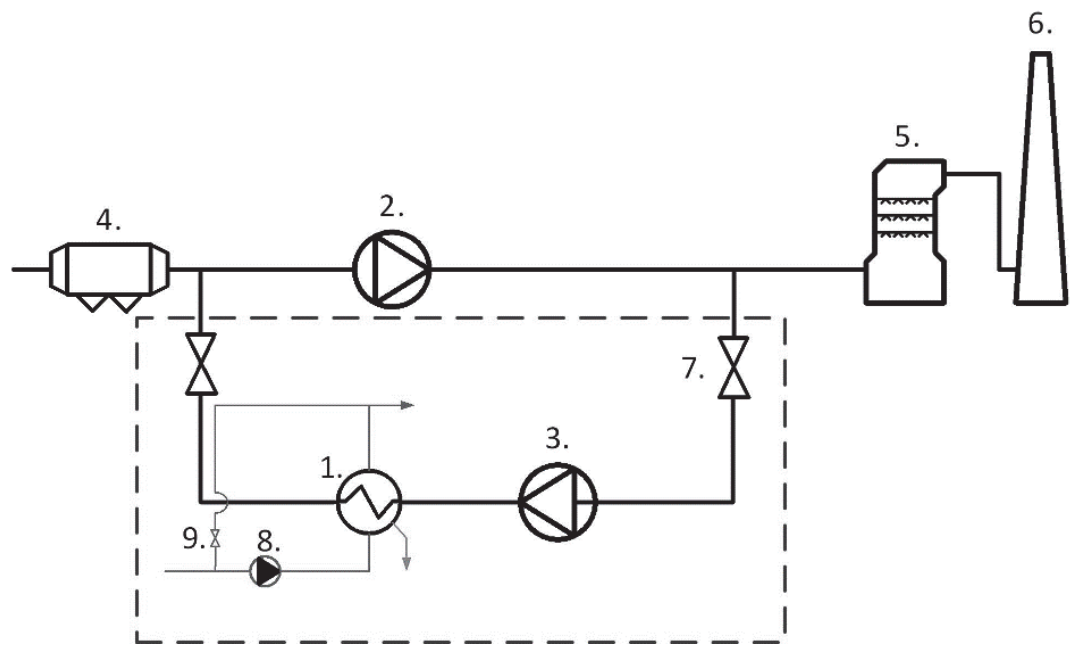

Fig. 1. Diagram of the pilot-scale plant for investigating waste heat recovery from flue gas; 1 - condensing heat exchanger, 2 - main fan in the flue gas duct, 3 - supporting fan, 4 - flue gas ash removal system, 5 - flue gas desulphurization system, 6 - chimney, 7 - shut-off gate valve, 8 - cooling water pump, 9 - control solenoid valve

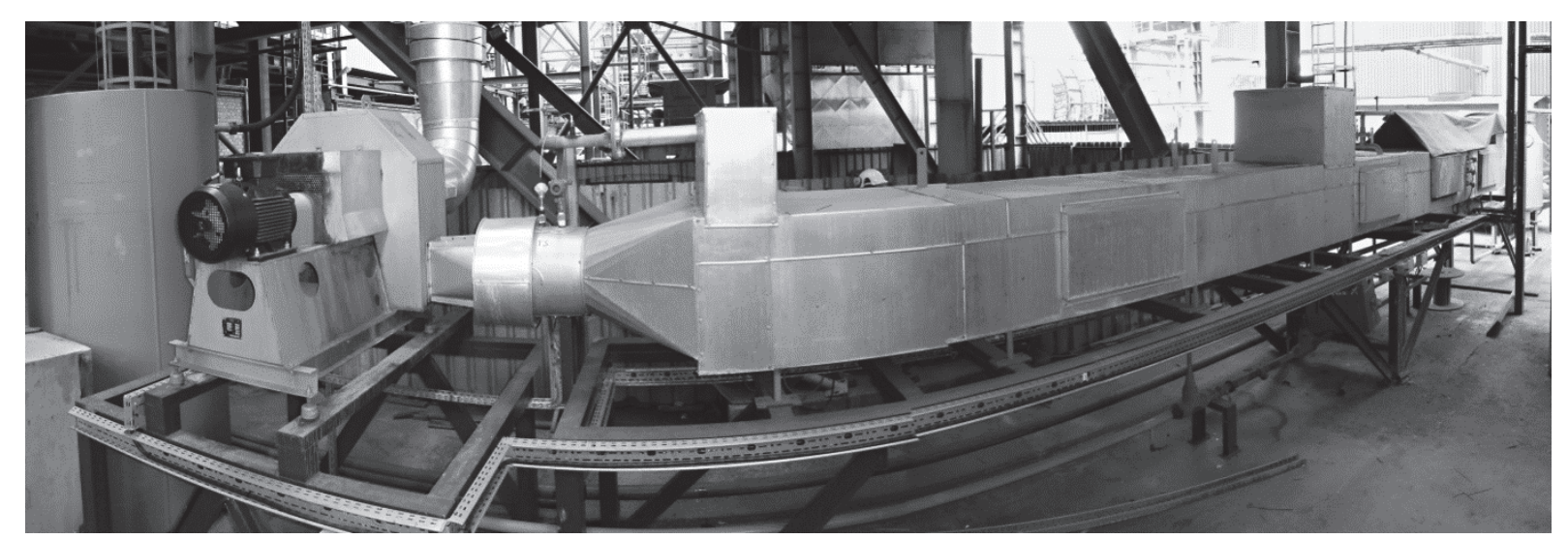

Fig. 2. View of the pilot-scale plant for investigating waste heat recovery from the flue gas

The flue gas flowing through the condensing heat exchanger was cooled down to a temperature below the dew point. As a result, condensation of water vapour contained in the flue gas took place and the condensate was being liquefied. The condensate was directed to the sewage system using a special pipeline. Heat was absorbed from the flue gas by water flowing through the heat exchanger.

\subsection{Condensing heat exchanger}

The main element of the pilot-scale plant was a condensing heat exchanger. The task of the heat exchanger was to cool down the flue gas coming from the power unit to a temperature below the dew point and to recover waste heat in the form of hot water with a temperature of $90{ }^{\circ} \mathrm{C}$. The heat 
exchanger consisted of two units of the condensing part and non-condensing part connected in series. It was a shell and tube heat exchanger with the cross-counter flow whose design parameters are given in Table 1.

Table 1. The design parameters of the condensing heat exchanger

\begin{tabular}{|l|c|c|}
\hline \multicolumn{1}{|c|}{ Quantity } & Unit & Value \\
\hline Thermal power of the heat exchanger & $\mathrm{kW}$ & 312 \\
\hline Water temperature at the outlet & ${ }^{\circ} \mathrm{C}$ & 90 \\
\hline Volumetric flow rate of flue gas & $\mathrm{m}_{\mathrm{n}}{ }^{3} / \mathrm{s}$ & 1.39 \\
\hline Volumetric flow rate of cooling water & $\mathrm{dm}^{3} / \mathrm{s}$ & 1.94 \\
\hline Average velocity of flue gas & $\mathrm{m} / \mathrm{s}$ & 11 \\
\hline Design heat transfer area & $\mathrm{m}^{2}$ & 77.5 \\
\hline Number of tubes & $\mathrm{pcs}$ & 40 \\
\hline Dimensions of the heat exchanger (length, width, height) & $\mathrm{mm}$ & $10000 \times 890 \times 485$ \\
\hline
\end{tabular}

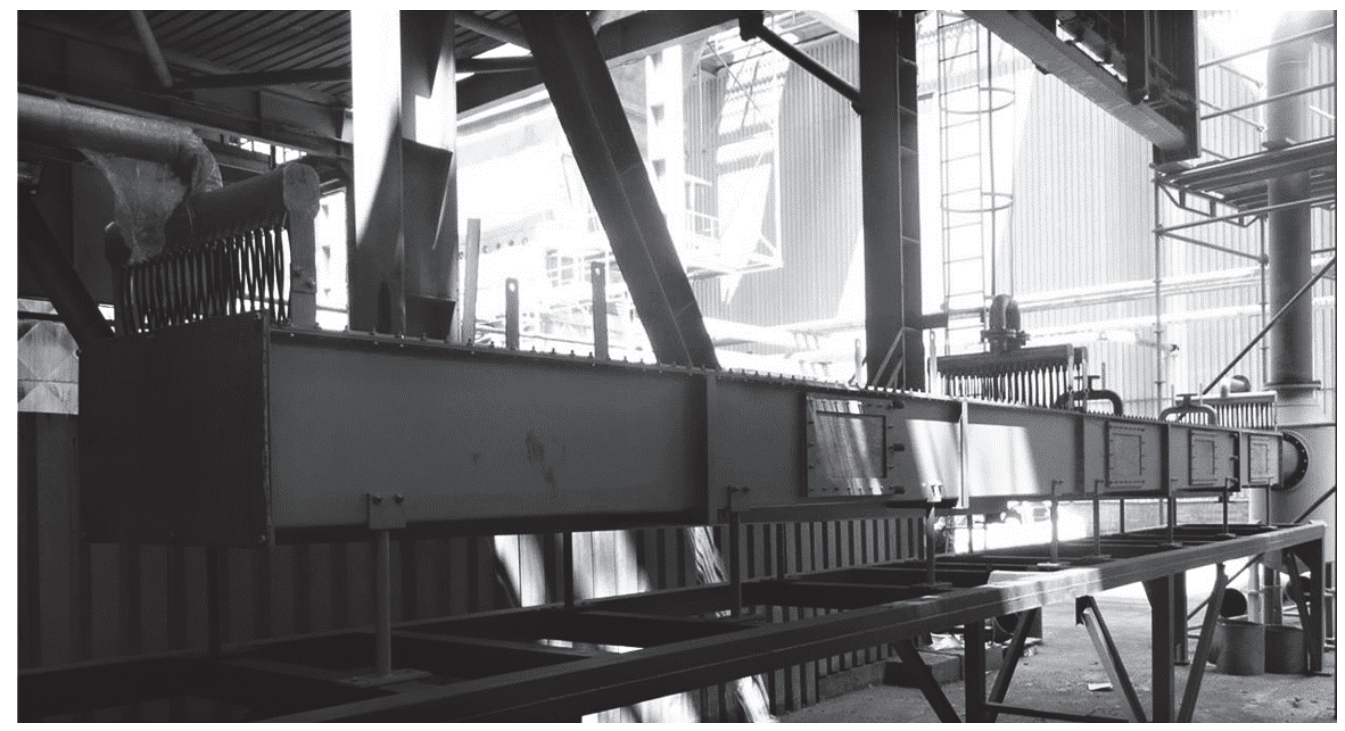

Fig. 3. View of the heat exchanger consisting of the condensing part and non-condensing part

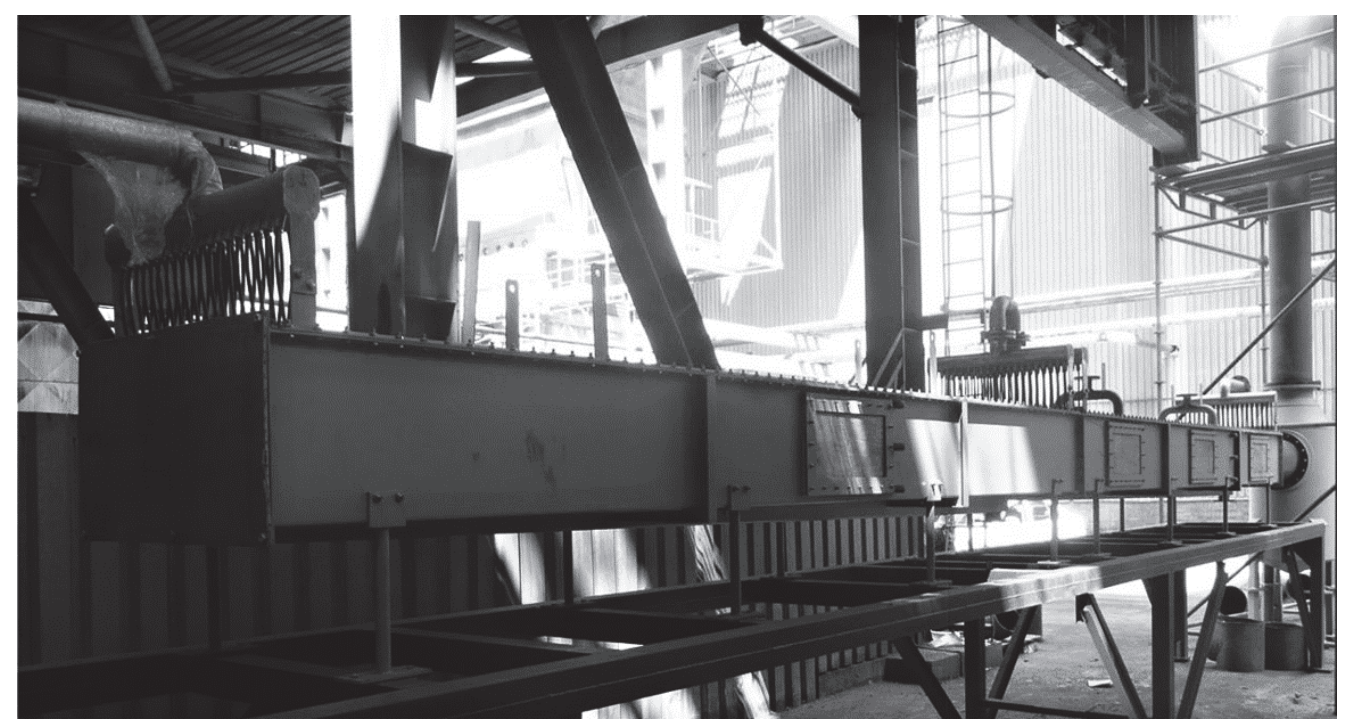

Fig. 4. View of the heat exchanger during the installation at the pilot-scale plant 
The shell of the heat exchanger was made of carbon steel protected with paint coatings, while the tubes with cooling water were made of Teflon. Flue gas flowed in the shell of the heat exchanger and cooling water flowed counter-currently through a system of 40 parallel coil pipes. Figures 3 and 4 present a general view of the condensing heat exchanger.

In order to collect the liquefied condensate along the length of the heat exchanger, a trough with a slight inclination was made, while three inspection ports were made in the part to observe the condensation of water vapour from the flue gas.

The heat exchanger was insulated with $50 \mathrm{~mm}$ thick lagging and galvanized aluminium sheet to reduce heat losses to the environment. Due to the aggressive action of flue gas flowing through the heat exchanger, its interior was covered with protective coating.

\subsection{System for supplying the heat exchanger with flue gas}

The condensing heat exchanger was supplied with the flue gas from the main duct of the BB-1150 boiler, while a radial fan was used to adjust the volumetric flow rate of the flue gas (Fig. 5).

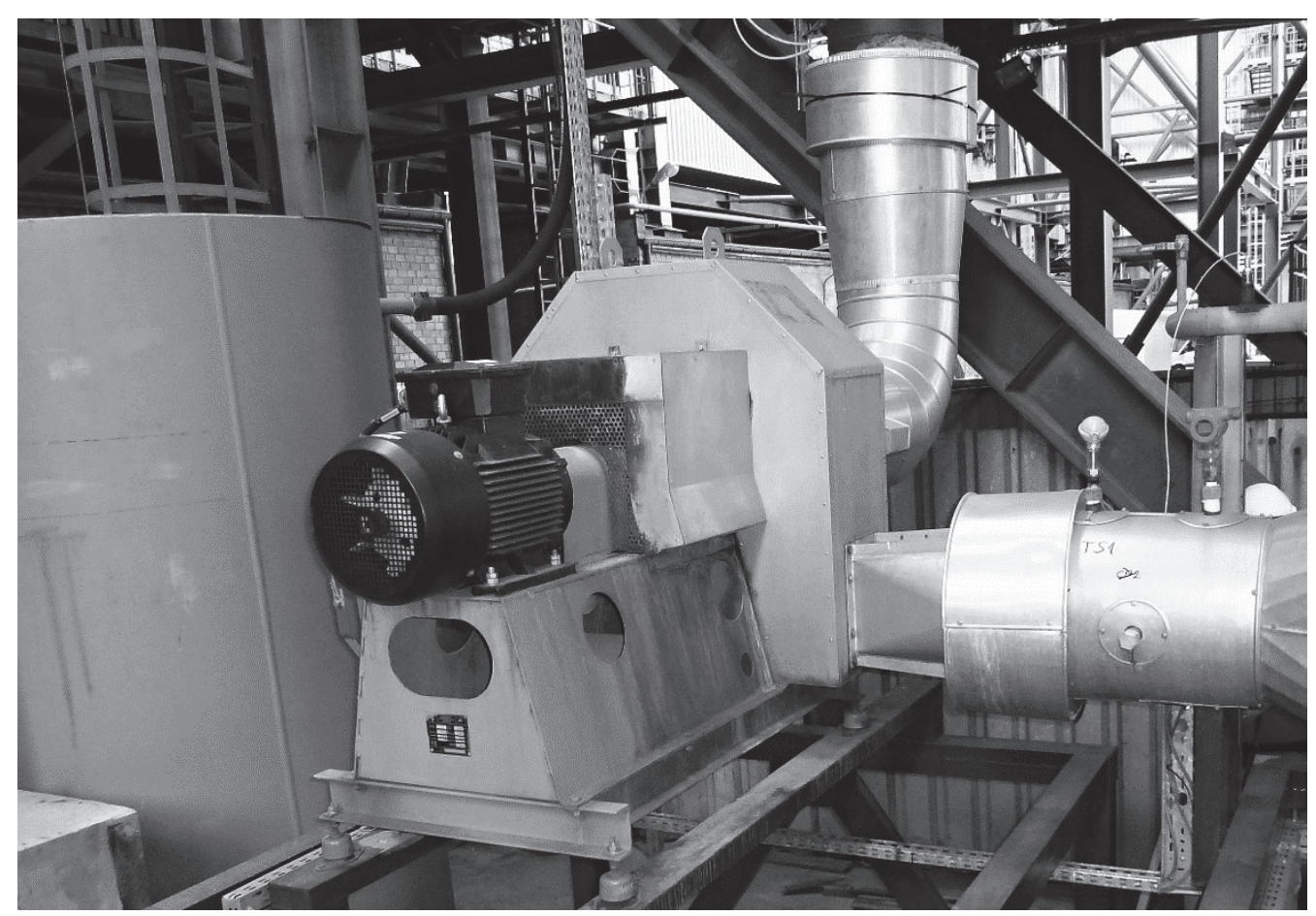

Fig. 5. Supporting fan installed at the test rig

\subsection{System for water cooling of the condensing heat exchanger}

The condensing heat exchanger was cooled with raw water flowing through the system of 40 coil pipes connected in parallel. In order to induce the flow, a system of two pumps was used - one of them was working, while the other was a backup. Frequency converters designed for continuous regulation of pressure and performance were built in the pump motors. They are controlled with a controller. In the event of a failure in the pump that is working, the backup pump is activated automatically. In the case of any failure of the converter, the pump switches to operation with maximum revolutions. In practice, such a system of operation protects the heat exchanger against a lack of water flow in the cooling pipes and their overheating. 
The system provided the ability to change the temperature of water supplying the heat exchanger. The purpose of the control system was to mix two streams, i.e. the stream of cooling water and the stream of hot water leaving the heat exchanger. By mixing these two streams in adequate proportions, water with the preset temperature was obtained at the inlet of the heat exchanger. Figure 6 shows a diagram of the water cooling system for the condensing heat exchanger.

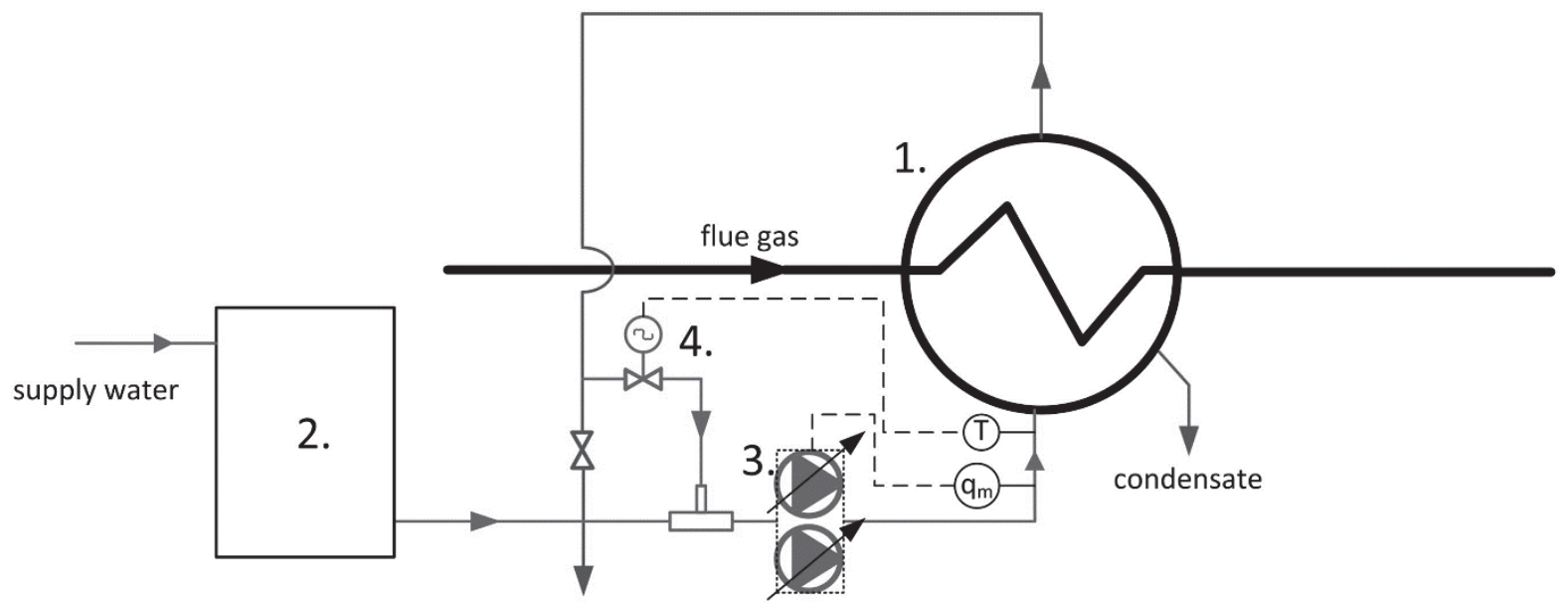

Fig. 6. Diagram of the water cooling system for the condensing heat exchanger; 1 - condensing heat exchanger, 2 - feed water tank, 3 - feed water pump system, 4 - control solenoid valve

Measuring points of the temperature of the inlet water and its volumetric flow rate were marked in the diagram. These measurements were used as input signals for the systems controlling the temperature and volumetric flow rate of water.

\subsection{Measuring instruments}

Measurement of the volumetric flow rate of the flue gas is one of the most difficult problems. The main ones are ash and high level of water vapour content in the gas. In addition, measurement is hindered by a disturbance in the velocity profile caused by a sudden change in the direction of the flue gas flow. Therefore, in order to measure this parameter, such a pressure grid was selected that is the least susceptible to the heterogeneity of the stream and requires the use of very short sections stabilizing the flow. The design of the pressure grid can be used to measure the difference between the total pressure and the static pressure. The differential pressure to be measured is delivered to converters via special collectors. The output signals of the pressure grid are the pressures the difference of which is equal to the dynamic pressure. A current signal goes out from the pressure transmitter. It specifies the volumetric flow rate of flue gas. Advantages of the pressure grid include a small flow resistance, shorter straight stabilizing sections upstream and downstream of the grid, as well as the possibility to measure the volumetric flow rate of gas with temperatures up to $400{ }^{\circ} \mathrm{C}$. Figure 7 presents a view of the pressure grid. The grid installed in the flue gas duct upstream of the supporting fan is shown in Fig. 8.

Sensors installed at the inlet and outlet for the flue gas and cooling water were used for measuring the temperature. The distribution of the temperature in the flue gas along the length of the heat exchanger and in its selected cross-section was measured too. In the non-condensing part of the exchanger, there were 6 measuring points in the axis of the heat exchanger as well as 3 points in the selected crosssection used for measuring the flue gas temperature at different heights of the heat exchanger. In the condensing part, there were 5 temperature sensors along the axis and 3 in the selected cross-section. 


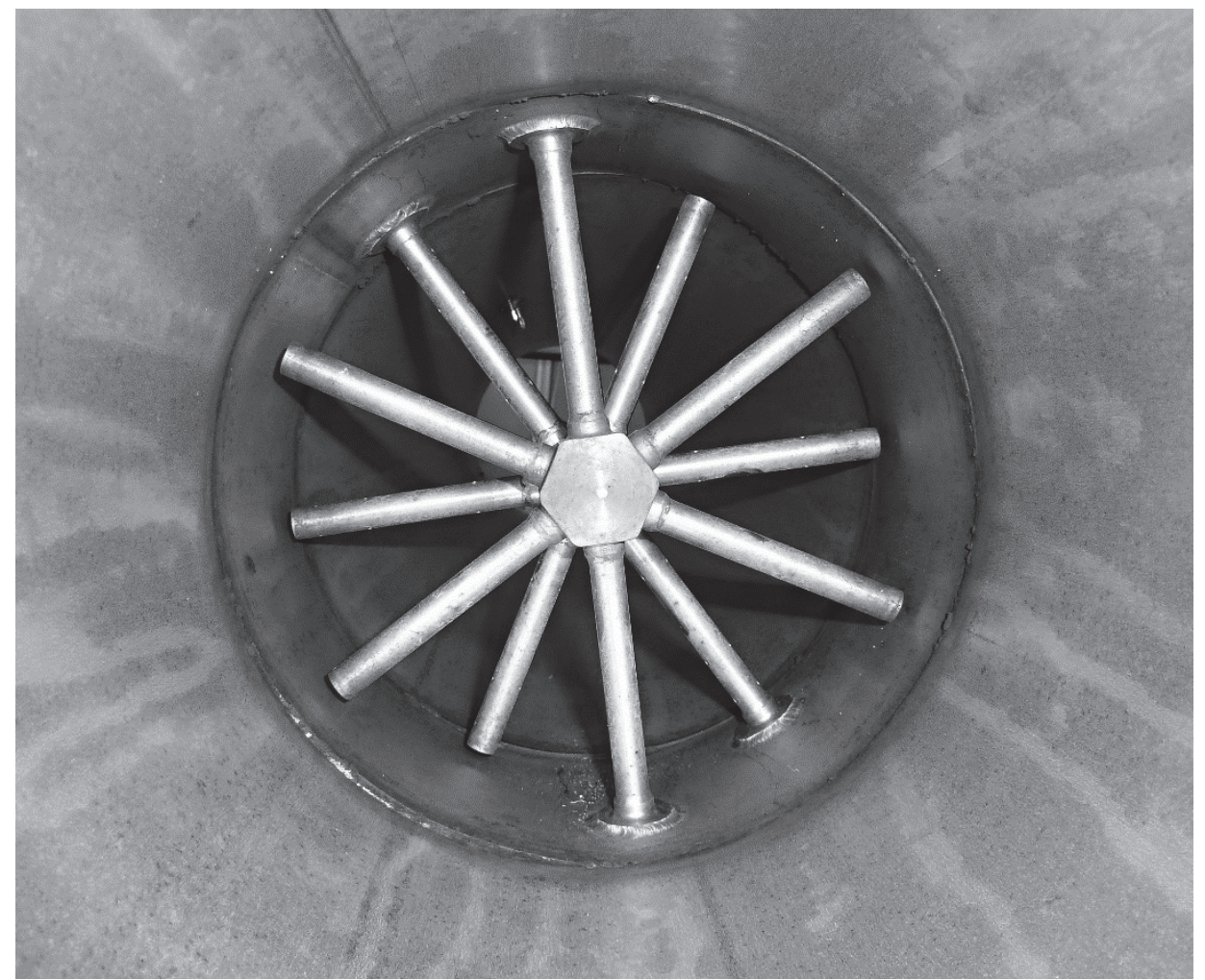

Fig. 7. Pressure grid for measuring the volumetric flow rate of flue gas

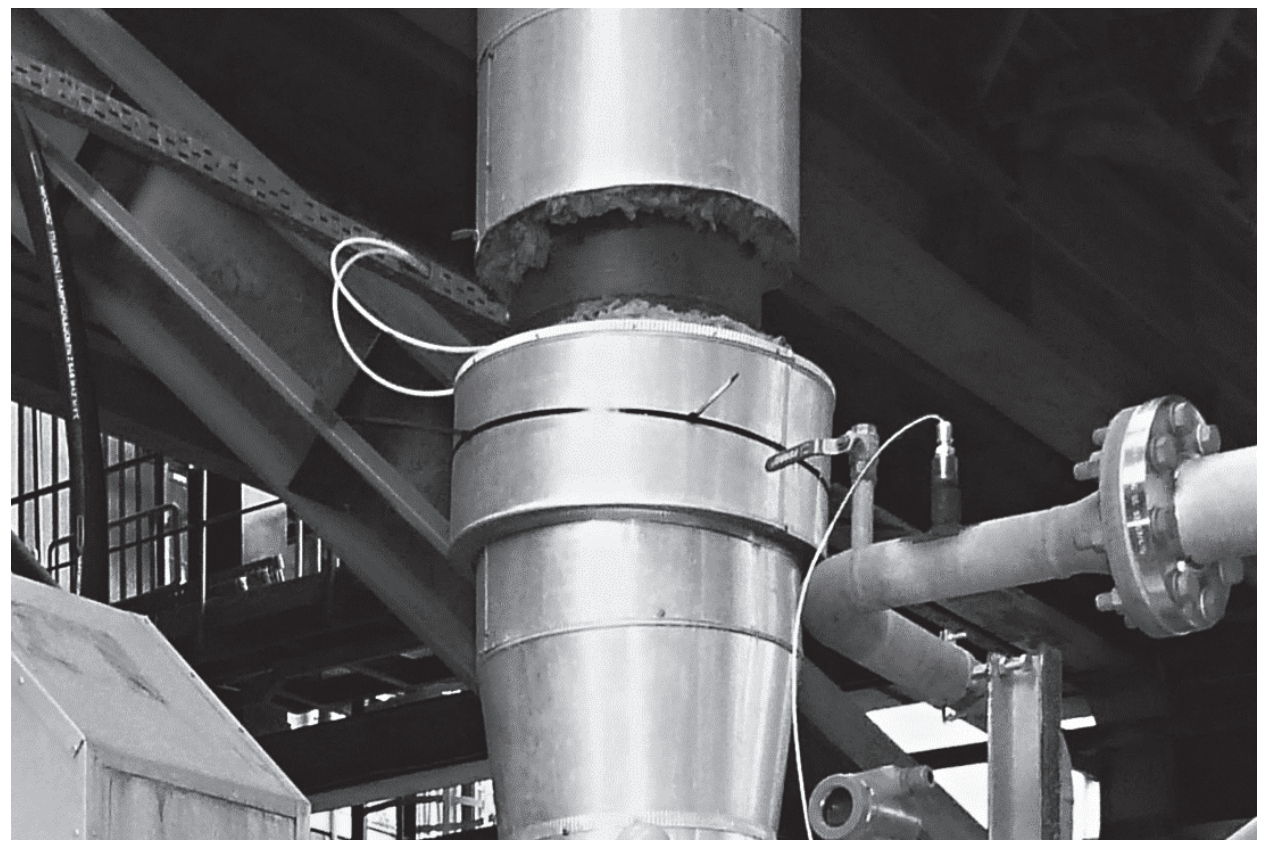

Fig. 8. View of the pressure grid installed in the pilot-scale plant

Vortex flowmeters were used to measure the volumetric flow rate of water that cooled the condensing heat exchanger as well as to measure the flow rate of the condensate. The flowmeters of this type are characterized by a high long-term stability, no zero drift and no moving parts. They generate small losses in the system and have high measurement dynamics. In addition, they have a high resistance to vibrations, temperature shocks, contaminated media and water impacts.

All the systems for controlling and collecting measurements in the pilot-scale plant for investigating the waste heat recovery from the flue gas were installed in a system rack. 


\section{BALANCE MATHEMATICAL MODEL OF A CONDENSING HEAT EXCHANGER}

\subsection{Process of condensation of water vapour from flue gas}

In order to investigate changes of the operating point of the condensing heat exchanger, a balance mathematical model of a condensing heat exchanger was developed (Szulc et al., 2012, Szulc et al., 2015). This model takes into account the condensation of water vapour in the presence of inert gas.

Apart from air, the most common gas containing water vapour is a wet flue gas. In such a mixture, the portion of the gas, which is not subject to phase transition, is called dry gas or inert gas. The total pressure of flue gas is the sum of the inert gas partial pressure and the water vapour partial pressure, which in the range of low pressures is described by the Dalton's law. Partial pressure of water vapour in flue gas can be used to determine the saturation temperature, at which the condensation process begins. This pressure is determined on the basis of the molar fraction of water vapour in the gas.

Based on the partial pressure of water vapour, the saturation temperature was calculated. It was adopted as the point, at which the condensation of water vapour contained in flue gas begins.

In order to determine the amount of moisture in flue gas, the mixing ratio was defined as the ratio of the mass of water vapour contained in the inert gas to the mass of the inert gas

$$
X=\frac{m_{v}}{m_{i}}
$$

$m_{v}$ - mass of water vapour, $m_{i}-$ mass of inert gas.

The process of condensation of water vapour in the presence of inert gas is a more complex phenomenon than condensation of pure water vapour and is described by the Mollier diagram.

The mass flow rate of the condensate being formed depends on the difference between the initial and final mixing ratio in flue gas and is expressed by the following relation

$$
q_{m c o n}=q_{m d r y}\left(X_{1}-X_{2}\right)
$$

The heat flux from flue gas is calculated as the difference between the initial and final enthalpy of flue gas using the equation

$$
Q_{g}=q_{m s p s}\left(i_{s p 1}-i_{s p 2}\right)
$$

The enthalpy of the flue gas is calculated as the sum of the enthalpy of inert gas and the enthalpy of water vapour

$$
i_{f}=i_{i}+X i_{v}
$$

In the process of water vapour condensation described in such a manner, the only variable parameter is the inert gas enthalpy (after exceeding the saturation temperature the moisture content in flue gas changes too). Thus, reference to the mass flow rate of inert gas in the mathematical model is convenient, because its value remains constant in the condensation process.

\subsection{Heat balance of a condensing heat exchanger}

In order to make a heat balance, the condensing heat exchanger was divided into two parts: the part without condensation and the part with the condensation of water vapour. 
The stream of flue gas was divided into two portions with the values of the mass flow rate of inert gas $q_{m d r y}$ and water vapour $X_{1} q_{m s d r y}$. Flue gas was cooled down to the final temperature $T_{2}$ and flowed further to the flue gas desulphurization system. If the temperature of flue gas $T_{2}$ was higher than the saturation temperature, the flow rates of both gases did not change. On the other hand, if the flue gas temperature $T_{2}$ was lower than the saturation temperature, condensation of water vapour occurs in the heat exchanger. The condensation of water vapour results in a change of its partial pressure, which in turn changed the mass flow rate of water vapour to the value of $X_{2} q_{m d r y}$.

The heat exchanger was cooled by water with the mass flow rate $q_{m w}$ and temperature $t_{1}$, which absorbs heat from flue gas. The cooling water leaving the condensing heat exchanger heated up to the temperature $t_{2}$. Thus, the heat flux transferred to cooling water is expressed by the equation

$$
Q_{w}=\left(i_{w 2}-i_{w 1}\right) q_{m w}
$$

where $i_{w 1}, i_{w 2}$ are initial and final enthalpies of water, respectively.

Similar equations will be used also to express the heat flux from inert gas (6) and water vapour (7) contained in flue gas.

$$
\begin{gathered}
Q_{f d r y}=\left(i_{f 1}-i_{f 2}\right) q_{m d r y} \\
Q_{v}=\left(X_{1} i_{v 1}-X_{2} i_{v 2}\right) q_{m d r y}
\end{gathered}
$$

Thus the total heat flux transferred from flue gas to water is the sum of Equations (6) and (7)

$$
Q_{f}=\left(i_{f 1}-i_{f 2}+X_{1} i_{v 1}-X_{2} i_{v 2}\right) q_{m d r y}
$$

If the condensation of water vapour occurs, the predominant component of the heat flux transferred to cooling water will be the heat associated with phase transition of water vapour, described by the equation

$$
Q_{c o n}=\left(X_{1}-X_{2}\right) q_{m d r y} r_{v}
$$

where $r_{v}$ is heat of evaporation.

Thermal power of the condensing heat exchanger is the sum of the sensible heat associated with the difference in enthalpies of flue gas at the inlet and at the outlet of the heat exchanger and the latent heat resulting from the phase transition occurring in water vapour. Considering the fact that water vapour contained in flue gas is to be subjected to condensation, flue gas must be cooled down to the saturation temperature, at which the process of condensation begins. Thus, heat exchangers of this type are characterized by much higher difference in the temperature between the inlet and outlet of flue gas as compared with heat exchangers without condensation of water vapour. This in turn leads to an increase in the amount of heat recovered from flue gas. The process of condensation of water vapour contained in flue gas begins at the saturation temperature. During this process the temperature is not constant as in the case of condensation of pure water vapour. This results from the presence of inert gas (air) in flue gas and from the fact that the volumetric fraction of moisture decreases as a result of condensation. However, the temperature difference is low in this case. Latent heat is proportional to the amount of the condensate formed, i.e. the difference between the moisture content in flue gas at the inlet and outlet of the heat exchanger. Thus, an important parameter increasing the amount of the waste heat recovered is the moisture content in flue gas, which primarily depends on the type of coal used. 


\section{RESULTS OF THE STUDIES AND THEIR ANALYSIS}

\subsection{Verification of the test rig}

Due to the fact that the pilot-scale test rig was provided with a number of control systems, the purpose of which as to maintain constant values of parameters such as mass flow rate of the flue gas, volumetric flow rate and temperature at the inlet of the heat exchanger of cooling water, as well as systems for data archiving, it was necessary to gradually incorporate individual components of the test rig and to test their operation. Figure 9 presents the time characteristics for the flue gas temperature at the outlet of the condensing heat exchanger.

Figure 9 shows that the temperature begins to stabilize at a constant level after about $35^{\circ}$ minutes of operation of the heat exchanger. It reaches a value of approx. $60^{\circ} \mathrm{C}$. This temperature is lower than the saturation temperature of the flue gas from the combustion of lignite. In this case the saturation temperature is $64{ }^{\circ} \mathrm{C}$. This is important information that indicates that the condensation of water vapour contained in flue gas occurs.

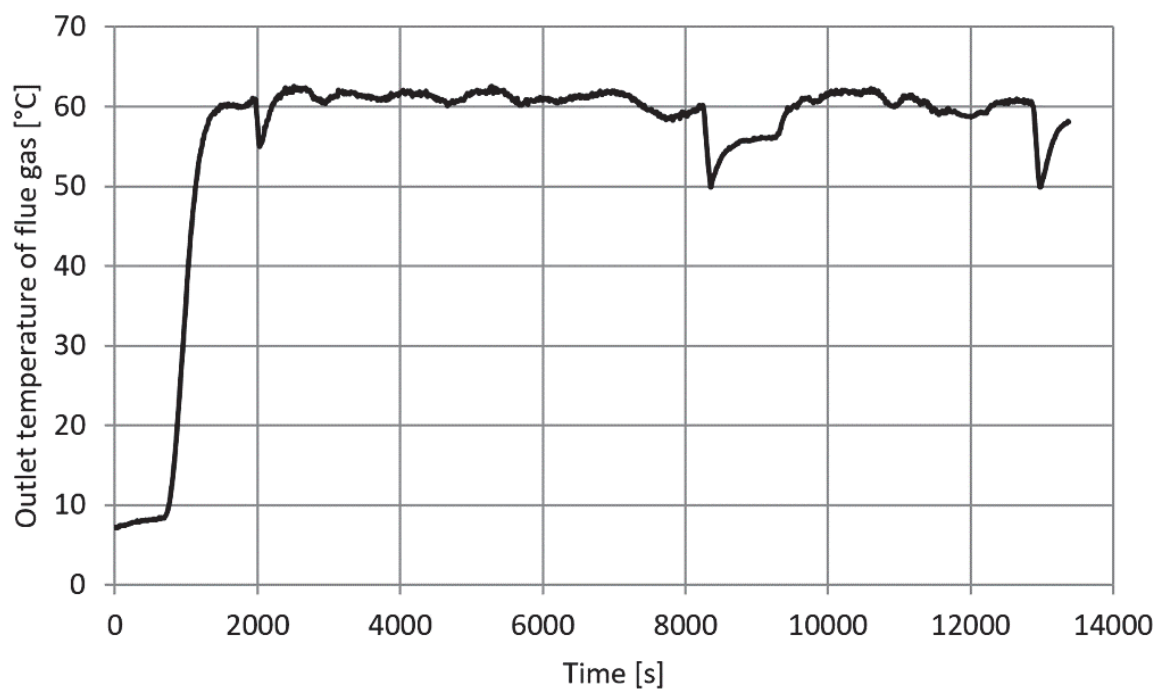

Fig. 9. Time characteristics for the flue gas temperature at the outlet of the heat exchanger

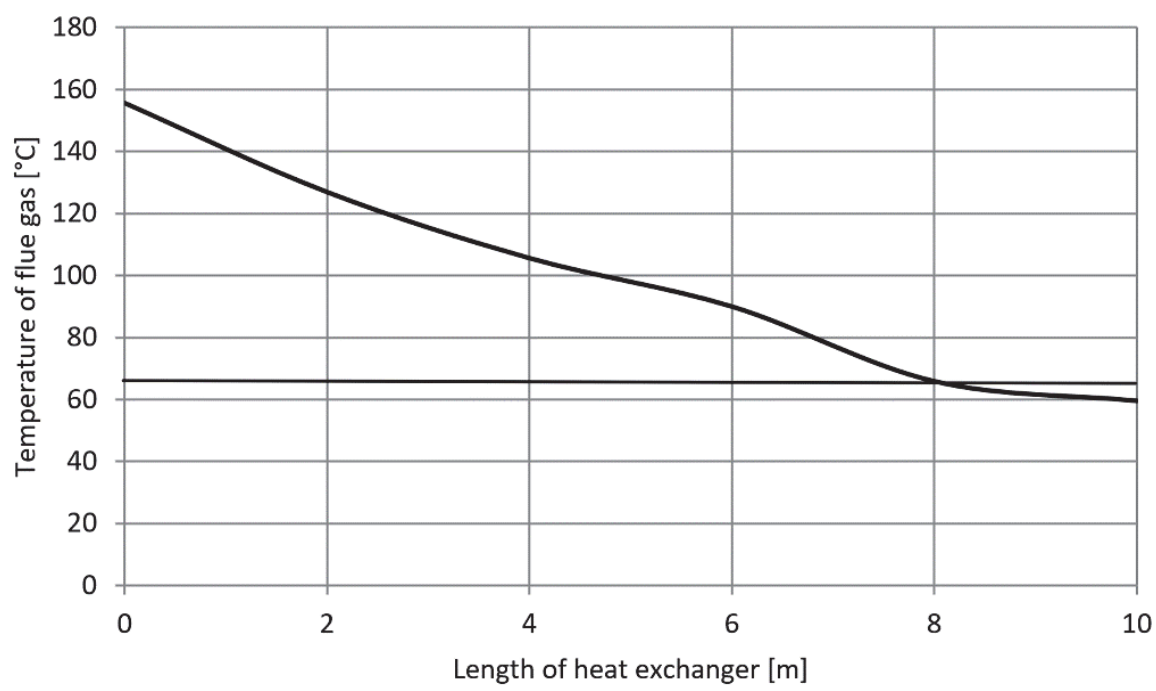

Fig. 10. Distribution of the flue gas temperature along the length of the heat exchanger 
Figure 10 shows the distribution of the flue gas temperature along the length of the heat exchanger. The saturation temperature of flue gas from the combustion of lignite is marked with a dotted line. From the presented characteristics it can be clearly seen in which part and at which length of the heat exchanger the condensation of water vapour occurs.

Figure 11 presents the time characteristic or the water temperature at the outlet pipe of the heat exchanger.

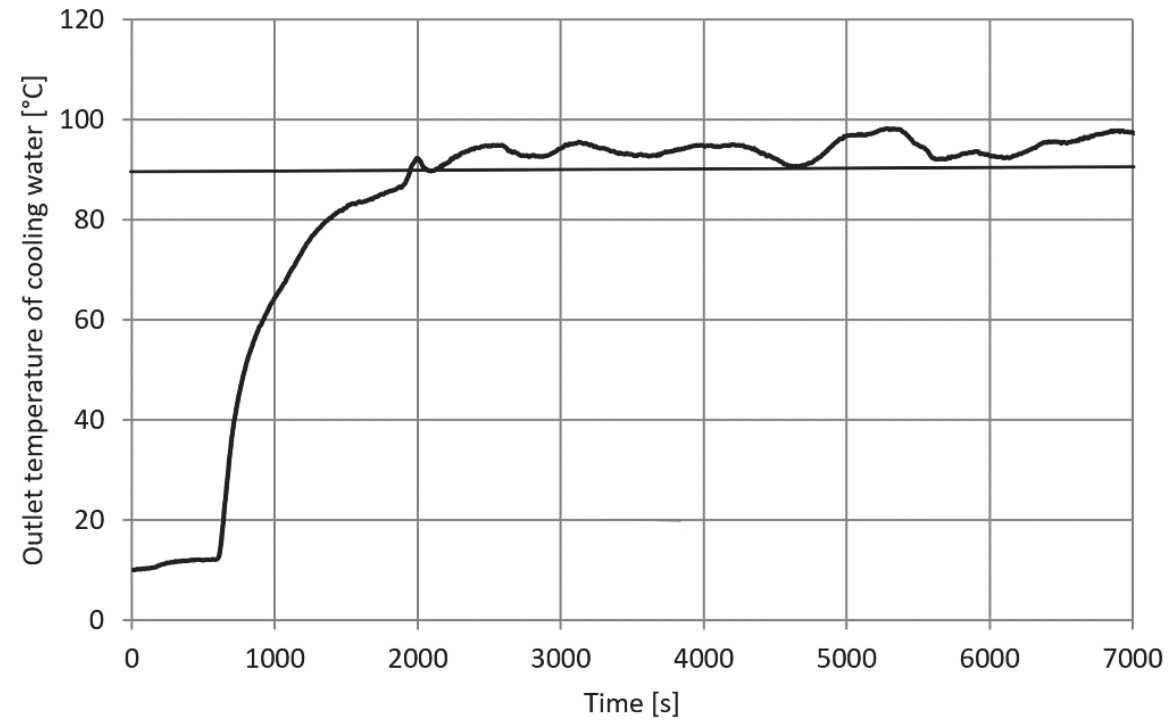

Fig. 11. Time characteristic of the temperature of water cooling the heat exchanger at the outlet pipe

This is a very important characteristic showing that the heat exchanger achieved the assumed goal, i.e. the temperature of cooling water which in this case exceeded even $90{ }^{\circ} \mathrm{C}$. Water achieved the temperature assumed after approx. 35 minutes of operation of the heat exchanger. The maximum value of the temperature was $98{ }^{\circ} \mathrm{C}$ for the volumetric flow rate of cooling water of $2.5 \mathrm{~m}^{3} / \mathrm{h}$.

\subsection{Studies on changes in thermal and flow parameters of the condensing heat exchanger}

Figures 12 and 13 show sample results of studies on changes in thermal and flow parameters of the condensing heat exchanger.

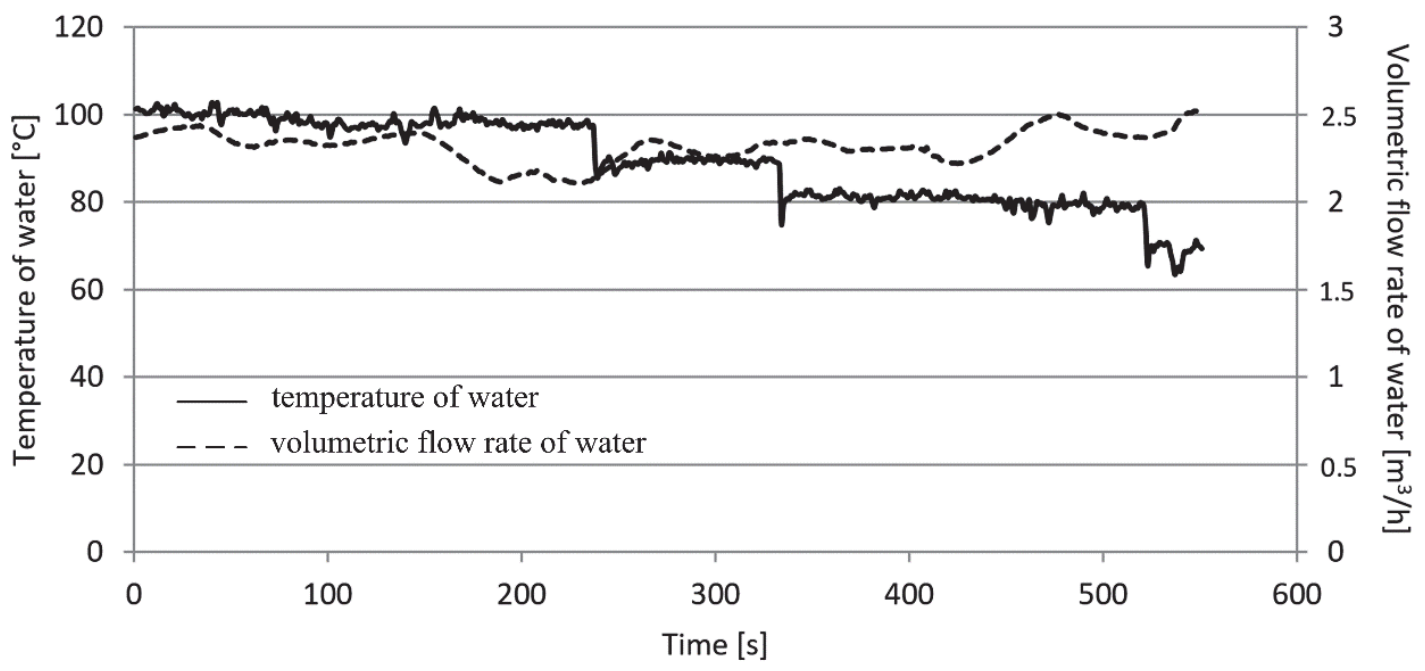

Fig. 12. The relationship between the flow rate and the cooling water temperature at the outlet of the heat exchanger as a function of time 
Figure 12 shows the relationship between the temperature of the outlet cooling water (dashed line) and the volumetric flow rate of water (solid line) over time. In the investigated range of the cooling water flow, the outlet temperature of water was slightly increasing along with a decrease in the volumetric flow rate. For values of the volumetric flow rate below $2 \mathrm{~m}^{3} / \mathrm{h}$, water temperature reached the threshold value of approximately $100^{\circ} \mathrm{C}$.

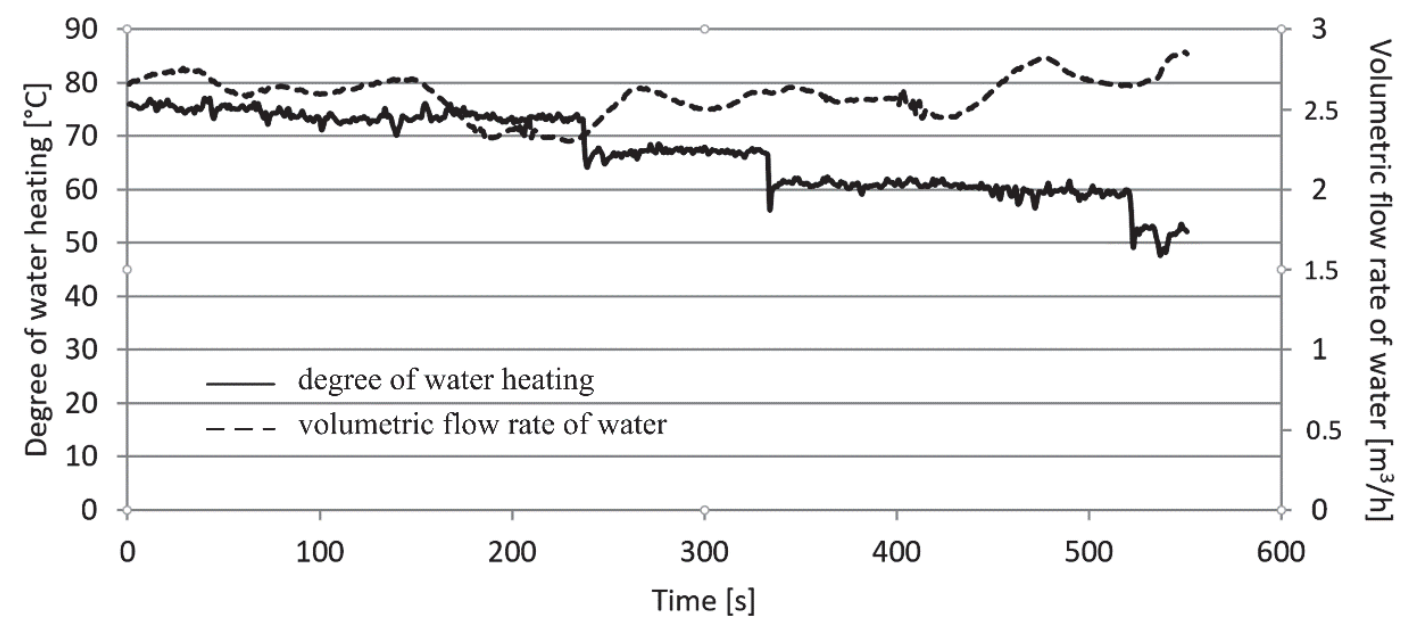

Fig. 13. Dependence between the flow rate of cooling water and the degree of heating it over time

Figure 13 shows similar characteristics presenting the volumetric flow rate of water (solid line) and the difference between the temperature at the outlet and inlet of the heat exchanger (dashed line), i.e. the degree of heating the cooling water over time depending on its volumetric flow rate. From Figure 13 it appears that along with a decrease in the volumetric flow rate of cooling water the degree of water heating increases and reaches the maximum value for a flow rate lower than $2 \mathrm{~m}^{3} / \mathrm{h}$.

\subsection{Impact of the volumetric flow rate of the flue gas on the operating point of the condensing heat exchanger}

The purpose of the study was to determine the impact of the volumetric flow rate of the flowing flue gas on the operating point of the heat exchanger and the amount of the waste heat recovered. This study consisted in changing the volumetric flow rate of the flue gas while keeping constant values of other parameters such as the temperature, moisture content in inlet of the flue gas, inlet temperature, and volumetric flow rate of cooling water. Values of the volumetric flow rate of the flue gas (measured upstream of the heat exchanger) were changed and then all thermal and flow parameters were measured in the steady state. Based on these results, characteristics were prepared.

Figure 14 shows the dependence of the moisture content of the flue gas at the outlet from the heat exchanger on the volumetric flow rate of the flue gas. Along with an increase in the volumetric flow rate of the flue gas, the moisture content increased due to the constant flow rate of cooling water and thus less intense process of water vapour condensation. This relationship was almost linear, as shown by the trend line.

Based on the moisture content in the flue gas at the inlet and outlet of the heat exchanger, the mass flow of the condensate formed was calculated. The dependence between the condensate mass flow rate and the volumetric flow rate of flowing flue gas is shown in Fig. 15.

As demonstrated in Fig. 15, an increase in the volumetric flow rate of the flue gas causes a decrease in the flow rate of the condensate generated. This dependence, similarly to the earlier one, is linear. Slight changes in the condensate mass flow rate were observed in the investigated range of changes in the volumetric flow rate of the flue gas. 


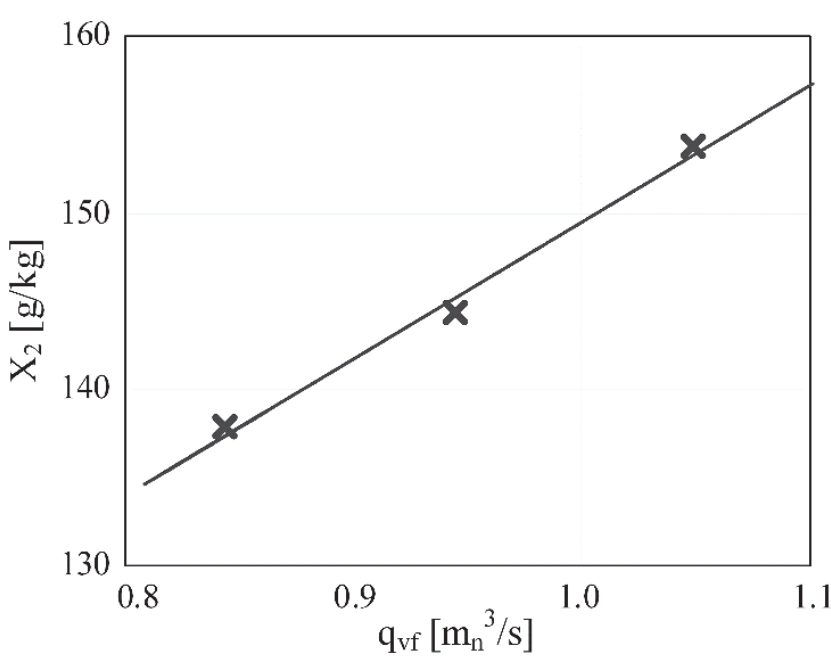

Fig. 14. Influence of the volumetric flow rate of the flue gas on the moisture content of flue gas

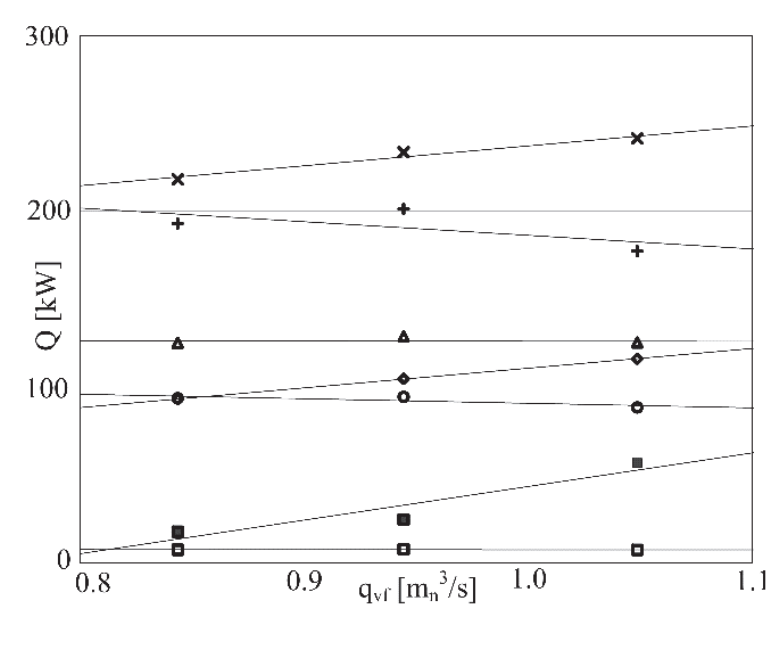

Fig. 15. The dependence between the condensate mass flow rate and the volumetric flow rate of the flue gas

Figure 16 shows a balance of heat fluxes in the condensing heat exchanger at a variable volumetric flow rate of the flue gas. Heat losses resulting from losses to the environment were calculated as well as the inaccuracy of calculations, averaging the physical properties of fluids and the uncertainty of measurements. The thermal balance of the condensing heat exchanger was calculated using Equations $(5-9)$.

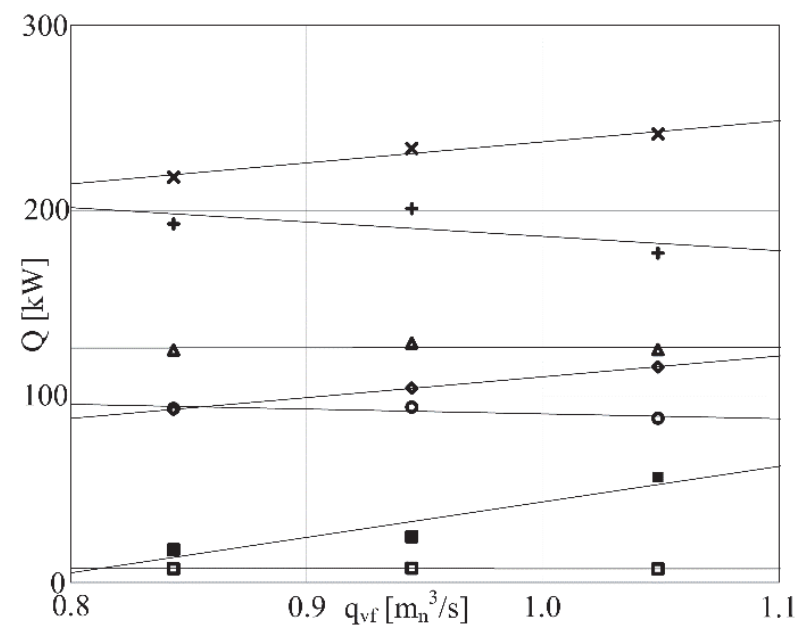

Fig. 16. The thermal balance of the condensing heat exchanger at a variable volumetric flow rate of the flue gas

The sign ( $\mathrm{x}$ ) indicates the total heat flux transferred from the flue gas. It consists of the heat flux transferred by inert gas $(\diamond)$ and the heat flux transferred by water vapour contained in the flue gas $(\triangle)$. The latter is the sum of the sensible heat resulting from the difference of the inlet and outlet enthalpy of water vapour and the latent heat associated with the phase transition $(O)$. The sign $(+)$ designates the heat flux transferred to cooling water and proportional to the difference of the enthalpy of water at the inlet and at the outlet of the heat exchanger. This flux at the same time was the waste heat recovered from the flue gas coming from the power unit. In addition, a slight heat flux was carried along with the condensate flowing out. This flux is marked $(\square)$. In order to calculate the heat losses, the heat flux transferred to cooling water and the heat flux carried away with the condensate were subtracted from the total heat flux of the flue gas. An increase in heat losses accompanying an increase in the volumetric flow rate of the flue gas was observed. However, in relation to the actual power of the heat exchanger these losses did not exceed the value of $60 \mathrm{~kW}$, i.e. approx. $23 \%$. In the investigated 
range of flows, an increase in the volumetric flow rate of the flue gas caused a slight change in the sensible heat flux transferred by the inert gas and thus in the total heat from the flue gas. The heat flux transferred to cooling water remained practically at a constant level due to small changes in the velocity of flowing the flue gas and thus constant heat exchange conditions.

\subsection{Impact of the volumetric flow rate of cooling water on the operating point of the condensing heat exchanger}

The purpose of the study was to determine the impact of the volumetric flow rate of cooling water on the operating point of the heat exchanger. This study consisted in changing the volumetric flow rate of cooling water while keeping constant values of other parameters such as temperature, moisture content at the inlet of the heat exchanger and volumetric flow rate of the flue gas. Three values of the volumetric flow rate of cooling water were set and then the thermal and flow parameters were measured in the steady state.

Figure 17 shows the dependence of the moisture content of the flue gas at the outlet of the heat exchanger on the volumetric flow rate of cooling water. Along with an increase in the volume of cooling water, the moisture content in the flue gas decreased. The water vapour condensation process was more intensive and outlet temperature of the flue gas decreased.

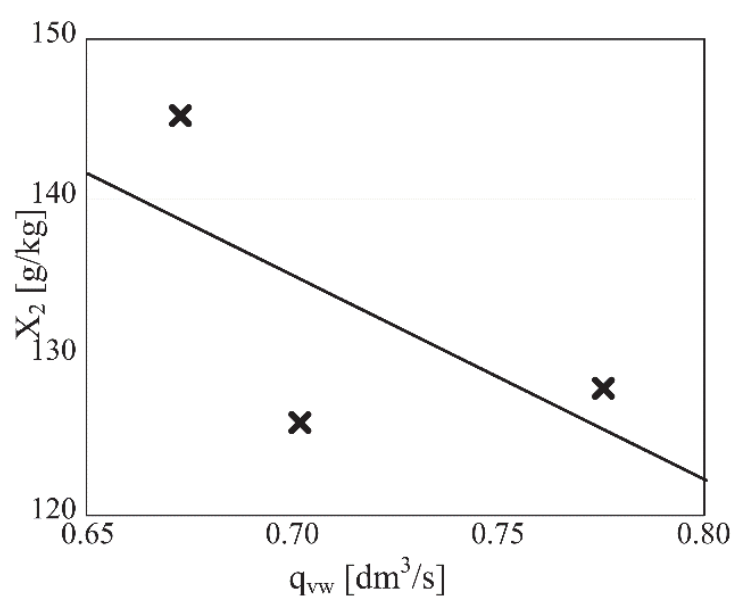

Fig. 17. Influence of the volumetric flow rate of cooling water on the mixing ratio of the outlet flue gas

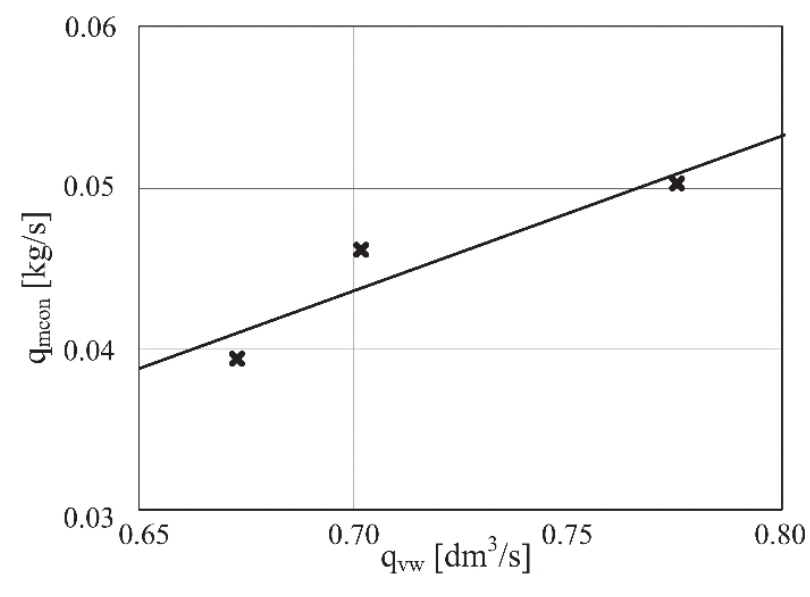

Fig. 18. The dependence between the condensate mass flow rate and the volumetric flow rate of cooling water

Based on the determined moisture content of the outlet and inlet flue gas, the mass flow rate of the condensate formed was calculated. The dependence between the condensate mass flow rate and the volumetric flow rate of cooling water is shown in Fig. 18.

An increase in the volumetric flow rate causes a growth of the flow rate of the condensate generated due to a decreasing moisture content of the outlet flue gas at a constant moisture content at the inlet. Similarly as in the case of changes in the volumetric flow rate of the flue gas, these dependences have a course similar to the linear one in the investigated range of changes in the volumetric flow rate of cooling water.

Figure 19 shows a balance of heat fluxes in the condensing heat exchanger at a variable volumetric flow rate of cooling water. The sign (x) indicates the total heat flux transferred from the flue gas. It consists of the heat flux transferred by inert gas $(\diamond)$ and the heat flux transferred by water vapour contained in the flue gas $(\triangle)$. In turn, the latter is the sum of the sensible heat resulting from the difference of the inlet and outlet enthalpy of water vapour and the latent heat associated with the phase 
transition $(\bigcirc)$. The sign $(+)$ designates the heat flux transferred to cooling water and proportional to the difference of the enthalpy of water at the inlet and at the outlet. This flux at the same time is the waste heat recovered from the flue gas coming from the power unit. In addition, a slight amount of heat is carried away together with the condensate flowing from the heat exchanger. This flux is marked ( $\square$ ). In order to calculate the heat losses, the heat flux transferred to cooling water and the heat flux carried away with the condensate were subtracted from the total heat flux of the flue gas.

The increase in the volumetric flow rate of cooling water caused a distinct increase in the latent heat and thus the total heat transferred by the flue gas. The main reason for this was a more intense process of liquefaction of the condensate from the flue gas. An important observation was made that the heat flux transferred to cooling water increased and thus the amount of the waste heat recovered was also greater. In this case, heat losses remained at a constant level of approx. $25-30 \mathrm{~kW}$, i.e. approx. 6-13\% of the actual power of the heat exchanger. The thermal balance of the condensing heat exchanger was calculated using Equations (5-9).

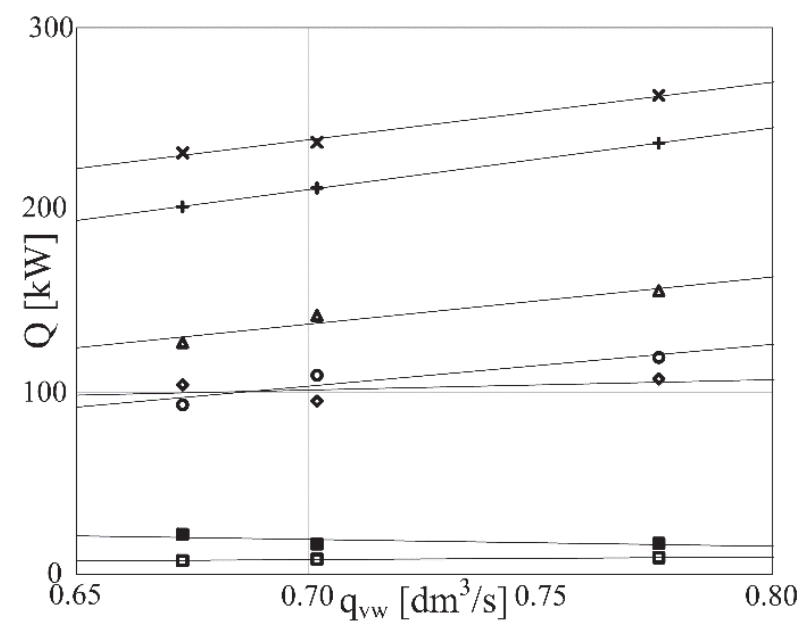

Fig. 19. The thermal balance of the condensing heat exchanger at a variable volumetric flow rate of cooling water

\section{SUMMARY}

The paper describes a pilot-scale plant for the recovery of low-temperature waste heat from the flue gas which was installed in a power unit of a lignite-fired power plant. In contrast to installations of this type currently operating in power plants, the system proposed by the authors uses the process of condensation of water vapour contained in the flue gas. If the condensation process is taken into account, the flux of the waste heat recovered will increase. The principle of operation of the plant was presented and its main elements were described. The condensing heat exchanger with a cross-counter flow of cooling water as well as the control and measurement systems were described. On the basis of the studies conducted on the pilot-scale plant it was found that the heat flux recovered was much higher than that used currently in systems without condensation of water vapour. In the case of the pilot-scale plant, the waste heat flux recovered exceeded $250 \mathrm{~kW}$, out of which the share of latent heat from the condensation of water vapour accounted for $60 \%$ of the total heat flux. The water temperature at the level of $90{ }^{\circ} \mathrm{C}$ allows to reuse the recovered heat in the power unit, e.g. in the regeneration system, for air heating, or for a district heating network.

The results presented in this paper were obtained under the studies co-financed by the National Centre for Research and Development under the Contract No. SP/E/1/67484/10 - Strategic Research Programme - Advanced technologies for energy generation: Development of a technology for highly efficient zero-emission coal-fired power units integrated with $\mathrm{CO}_{2}$ capture from flue gas. 


\section{REFERENCES}

Chaojun W., Boshu H., Linbo Y., Xiaohui P., Shinan Ch., 2014. Thermodynamic analysis of a low-pressure economizer based waste heat recovery system for a coal-fired power plant. Energy, 65, 80-90. DOI: 10.1016/j.energy.2013.11.084.

Chaojun W., Boshu H., Shaoyang S., Ying W., Na Y., Linbo Y., Xiaohui P., 2012. Application of a low pressure economizer for waste heat recovery from the exhaust flue gas in a $600 \mathrm{MW}$ power plant. Energy, 48, $196-202$. DOI: 10.1016/j.energy.2012.01.045.

Dexin W., Ainan B., Kunc W., Liss W., 2012. Coal power plant flue gas waste heat and water recovery. Appl. Energy, 91, 341-348. DOI: 10.1016/j.apenergy.2011.10.003.

Rączka P., Wójs K., 2014. Methods of thermal calculations for a condensing waste-heat exchanger. Chem. Process Eng., 35, 447-461. DOI: 10.2478/cpe-2014-0034.

Szulc P., Tietze T., Wójs K., 2013. The influence of the volumetric flow of exhaust gas on low temperature waste heat recovered in condensing heat exchanger, In: Węglowski B., Duda P. (Eds.), Analysis of power energy systems. Publishing House of the Cracow University of Technology, Kraków, 317-330, (in Polish).

Szulc P., Tietze T., Wójs K., 2012. Balance model of the counter-current heat exchanger with horizontal arrangement of the cooling tubes, In: Wójs K., Szulc P., Tietze T. (Eds), Current directions of power energy development. Publishing House of the Wrocław University of Technology, Wrocław, 113-123 (in Polish).

Szulc P., Tietze T., Wójs K., Numerical analysis of a waste heat recovery process with account of condensation of steam from flue gases. Arch. Civil Mech. Eng., 2015, 15, 1017-1023. DOI: 10.1016/j.acme.2015.05.002.

Tietze T., Szulc P., Lepszy M., Wójs K., 2014. Test rig of the heat exchanger to recover waste heat from the exhaust gas. Rynek Energii, 3(112), 93-100 (in Polish).

Wójs K., Szulc P., Tietze T., Sitka A., 2010. Concept of a system for waste heat recovery from flue gases in a coal-fired power plant, J. Energy Science, 1(1), 191-200. Available at: OAI: www.dbc.wroc.pl:4928.

Wójs K., Szulc P., Tietze T., 2015. The recovery of low temperature waste heat from the exhaust gas, In: Wójs K. (Ed.), Recovery and development of low temperature waste heat from the exhaust gas (Odzysk $i$ zagospodarowanie niskotemperaturowego ciepla odpadowego ze spalin wylotowych). Wydawnictwo Naukowe PWN, Warszawa, 1-111 (in Polish).

Xiaojun S., Defu C., Brian Agnew b, Jianmin Gao, 2011. An investigation of the performance of compact heat exchanger for latent heat recovery from exhaust flue gases. Int. J. Heat Mass Transfer 54, 606-615. DOI: 10.1016/j.ijheatmasstransfer.2010.09.009.

Received 13 October 2015

Received in revised form 21 July 2016

Accepted 14 October 2016 